\title{
Circular Monopole Reconfigurable Antenna with Notch Band Filter Characteristics
}

\author{
M Vijaya Lakshmi, P Pardhasaradhi and B T P Madhav*
}

Department of ECE, Koneru Lakshmaiah Education Foundation, AP, India

Received 9 December 2017; Accepted 29 November 2018

\begin{abstract}
This article presents the design and analysis of frequency tunable circular monopole antenna with notch band characteristics. The proposed antenna consisting of slots on the radiating element to attain notch bands in the ultra wideband (UWB). The dimensions of the slots are properly adjusted and optimized to obtain the desired band rejection response. Two PIN diodes are connected between stubs and the feed line to obtain the tenability in the notch bands. The switching operation between the diodes, controlling the length of the radiating structure and intern affecting the reconfigurable behaviour in the antenna. The overall dimension of the antenna is very compact and occupying around $44 \mathrm{X} 40 \mathrm{X} 1.6 \mathrm{~mm}$ on FR4 substrate with dielectric constant 4.4 and loss tangent 0.02 . The proposed antenna initially notching WiMAX and WLAN operating bands of 3.1-3.7 GHz and 5.1-5.8 GHz and frequency tenability is analyzed with diodes switching condition to notch other communication application bands. The simulation results of reflection coefficient, radiation patterns and gain obtained from CST microwave studio and real-time measurements from prototyped antenna demonstrates the excellent working characteristics of the notch band antenna with tunable behaviour.
\end{abstract}

Keywords: Circular Monopole, Computer Simulation Technology (CST), Notch Band, Reconfigurability, Tunability, WIMAX, Wireless LAN (WLAN)

\section{Introduction}

Ultra wideband (UWB) technology covers most of the wireless communication application bands and provides new challenges and opportunities to antenna engineers. The UWB can handle hundreds of mbps with its wide frequency bandwidth and it offers very reliable and safe communication platform with low energy density [1-2]. In 2002, Federal communications commission (FCC) allocated 3.1-10.6 GHz as UWB range. As per FCC any signal with $500 \mathrm{MHZ}$ spectrum can be considered in UWB systems. Compared to narrow band carriers UWB systems can deliver data at high rate [3-4].

To overcome electromagnetic interference (EMI) in certain operations we require rejection of unwanted frequency bands with the help of band reject filters [5-10]. The reliable UWB system must fulfil the requirements of wide bandwidth with high gain and low complexity with good radiation efficiency. Researchers are proposing number of models of UWB antennas with notch band characteristics in different ways [11-14]. In this process numerous slot models with defected ground structures are proposed with reduction in the overall size of the antenna model [15-16]. The coverage bandwidth of UWB is also shared by some other narrow band services like WLAN, EEE 802.11 a, HyperLAN2 etc. To achieve multiple notch bands, we should model the antenna in an efficient way with compact size [17-19].

This paper focus on such antenna model, which can notch multiple bands with its tuneable behaviour. To tune notching bands with respect to operating bands a novel

*E-mail address: btpmadhar@kluniversity.in ISSN: 1791-2377 @ 2018 Eastern Macedonia and Thrace Institute of Technology. All rights reserved. doi:10.25103/jestr.115.17 structure of circular monopole with stubs are chosen in this case and by placing diodes at junctions, we achieved frequency switching characteristics. Initially basic notch antenna with two slots on the radiating element was proposed to get notch bands at WiMAX and WLAN and after that the diodes are switched between specific values to get tunability in the notch bands. The comparative analysis with respect to the previously published antenna models are presented in Table 1 for the reference.

Table 1. A comparison of various notch band antennas with proposed antenna model

\begin{tabular}{|c|c|c|c|c|}
\hline $\begin{array}{l}\text { Ref. } \\
\text { No }\end{array}$ & Size & Feed & $\begin{array}{l}\text { Device } \\
\text { Used }\end{array}$ & $\begin{array}{l}\text { Notch } \\
\text { Band }\end{array}$ \\
\hline [3] & $34 \times 34$ & Microstrip & PIN diode & $3-4 \mathrm{GHz}$ \\
\hline [8] & $48 X 42$ & Microstrip & PIN diode & 4-6 GHz \\
\hline [9] & $52 \times 48$ & Coaxial & Varactor & $5-6 \mathrm{GHz}$ \\
\hline [17] & $58 \times 52$ & CPW & $\begin{array}{l}\text { Varactor } \\
\text { diode }\end{array}$ & 4-7 GHz \\
\hline $\begin{array}{l}\text { Proposed } \\
\text { Model }\end{array}$ & $47 X 40$ & Microstrip & PIN diode & $\begin{array}{l}3.1-3.7 \\
\mathrm{GHz} \\
5.1-5.8 \\
\mathrm{GHz}\end{array}$ \\
\hline
\end{tabular}

\section{Antenna Geometry and Design}

The antenna model is designed with computer simulation technology (CST) tool and the design methodology is presented in this section. Fig 1(a) shows the circular monopole antenna for UWB applications and Fig 1(b) and 1(c) shows the slots based modified notch band monopole antenna top side and bottom side. The slots are etched on the radiating element systematically to achieve the notch band characteristics at WiMAX and WLAN bands. The monopole 
antenna is modelled on FR4 substrate with dielectric constant 4.4 and loss tangent 0.02 . Defected ground structure is used in this model to improve the bandwidth. The dimensions of the basic antennas of UWB and notch models are presented in Table 2. The feed line dimensions of 2.6 $\mathrm{mm}$ X $20.3 \mathrm{~mm}$ are used to achieve impedance of $50 \mathrm{ohms}$.

The actual radius of the circular patch was calculated from [13]

$$
R=\frac{F}{1+\sqrt{\pi \varepsilon_{e f f} F\left[\ln \frac{F \pi}{2 h}+1.7726\right]}}
$$

Where

$F=\frac{8.791 * 10^{9}}{f_{r} \sqrt{\varepsilon_{e f f}}}$

$\mathrm{f}_{\mathrm{r}}=$ Resonant Frequency in $\mathrm{Hz}, \varepsilon_{\text {eff }}=$ Effective dielectric constant, $\mathrm{R}=$ Radius of the patch, $\mathrm{h}=$ Height of the substrate in $\mathrm{mm}$.

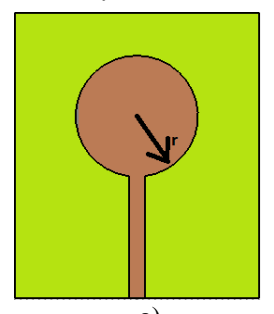

a)

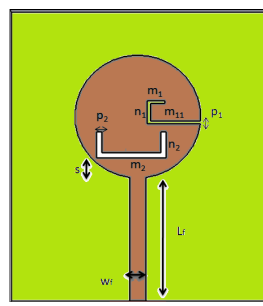

b)

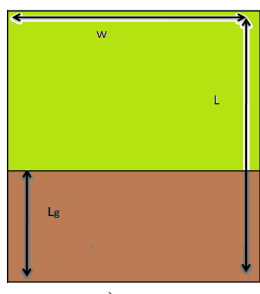

c)
Fig 1. Basic Circular Monopole Antenna Model, (a) Circular Monopole, (b) Top side of Notch Band Circular Monopole, (c) Bottom side with DGS

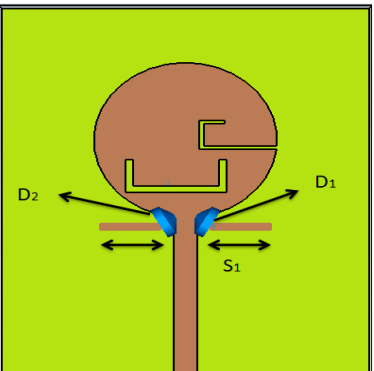

(a)

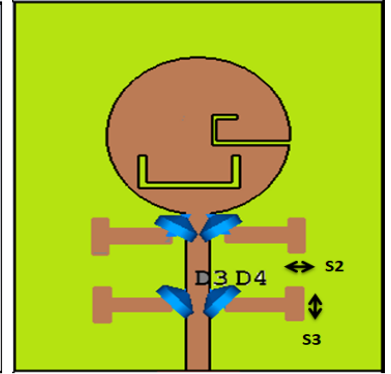

(b)
Fig 2. Reconfigurable Notch Band Antenna, (a) Basic reconfigurable notch band antenna, Proposed reconfigurable notch band antenna

Table 2. Antenna Dimensions

\begin{tabular}{c|c|c|c|c|c}
\hline $\begin{array}{c}\text { S. } \\
\text { No }\end{array}$ & $\begin{array}{c}\text { Antenna } \\
\text { Parameter }\end{array}$ & $\begin{array}{c}\text { Dimensions } \\
\text { in mm }\end{array}$ & $\begin{array}{c}\text { S. } \\
\text { No }\end{array}$ & $\begin{array}{c}\text { Antenna } \\
\text { Parameter }\end{array}$ & $\begin{array}{c}\text { Dimensions } \\
\text { in mm }\end{array}$ \\
\hline $\mathbf{1}$ & $\mathrm{L}$ & 47 & 9 & $\mathrm{~m}_{1}$ & 2.8 \\
$\mathbf{2}$ & $\mathrm{W}$ & 40 & 10 & $\mathrm{~m}_{11}$ & 8.5 \\
$\mathbf{3}$ & $\mathrm{Lf}$ & 20.3 & 11 & $\mathrm{n}_{1}$ & 3.8 \\
$\mathbf{4}$ & $\mathrm{Wf}$ & 2.6 & 12 & $\mathrm{~m}_{2}$ & 11 \\
$\mathbf{5}$ & $\mathrm{Lg}$ & 19.3 & 13 & $\mathrm{n}_{2}$ & 4.2 \\
$\mathbf{6}$ & $\mathrm{S}, \mathrm{S}_{1}$ & 3,6 & 14 & $\mathrm{p}_{1}$ & 0.5 \\
$\mathbf{7}$ & $\mathrm{r}$ & 10 & 15 & $\mathrm{P}_{2}$ & 0.8 \\
$\mathbf{8}$ & $\mathrm{S} 2$ & 1.5 & 16 & $\mathrm{~S} 3$ & 2 \\
\hline
\end{tabular}

Slots are loaded on the radiating element to filter certain bands, which avoids the interference between UWB and other wireless services. To obtain the desired bands rejection, the slot dimensions are optimized with following equations.

$\left(\mathrm{m}_{1}+\mathrm{m}_{11}+\mathrm{n}_{1}-2 \mathrm{p}_{1}\right)=\mathrm{L}_{1}=\mathrm{c} / 4 \mathrm{f}_{\text {Notch }} \sqrt{ } \mathcal{E}_{\text {eff }}$
Where ' $L_{1}$ ' is the length of the upper slot, ' $c$ ' is the velocity of light, $\mathrm{f}_{\mathrm{Notch}}$ is the notch frequency and $\varepsilon_{\text {eff }}$ is the effective dielectric constant.

$\varepsilon_{\text {eff }}=\left(\varepsilon_{\mathrm{r}}+1\right) / 2$

The lower slot dimensions are optimized from the following equations

$\left(\mathrm{m}_{2}+2 \mathrm{n}_{2}-2 \mathrm{p}_{2}\right)=\mathrm{L}_{2}=\lambda_{\text {guided }} / 2$

Here

$\lambda_{\text {guided }}=\mathrm{c} / \mathrm{f}_{\text {Notch }} \sqrt{ } \varepsilon_{\text {eff }}$

Where ' $\lambda_{\text {guided }}$ ' is the notch frequency guided wavelength and ' $\mathrm{L}_{2}$ ' is the lower slot length.

Switches are connected in the form of diodes on both sides of the feed line as shown in Fig 2. Diodes are connected between the feed line and the stubs to attain the frequency reconfigurability nature in the antenna structure. A detailed analysis of the proposed antenna model with respect to switching characteristics is presented in subsequent section.

\section{Results and Analysis}

The analysis of notch band antenna is carried with simulation tool CST microwave studio. The reflection coefficient curve for basic circular monopole antenna is presented in Fig 3. The circular monopole antenna operating band is from 2.4 to $11 \mathrm{GHz}$ with bandwidth of 8.6 and impedance bandwidth of $69 \%$. The reflection coefficient of notch band circular monopole is presented in Fig 4. Notch band characteristics are obtained at two bands (WiMAX of 3.1-3.7 GHz \& WLAN of 5.1-5.8 GHz).

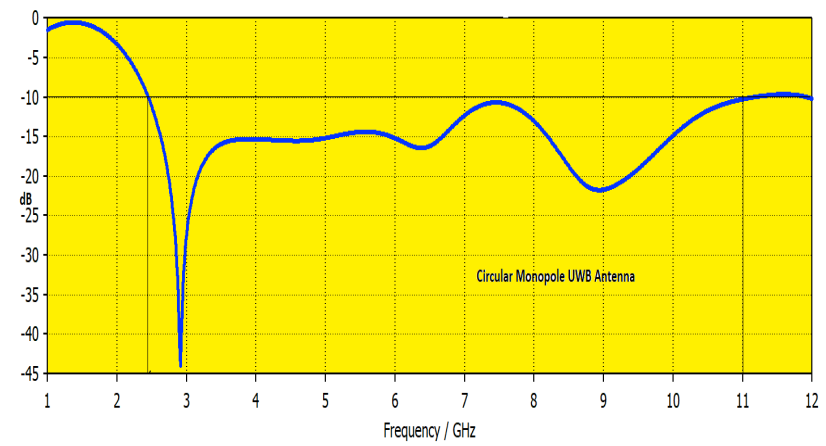

Fig 3. Reflection coefficient of circular monopole UWB antenna

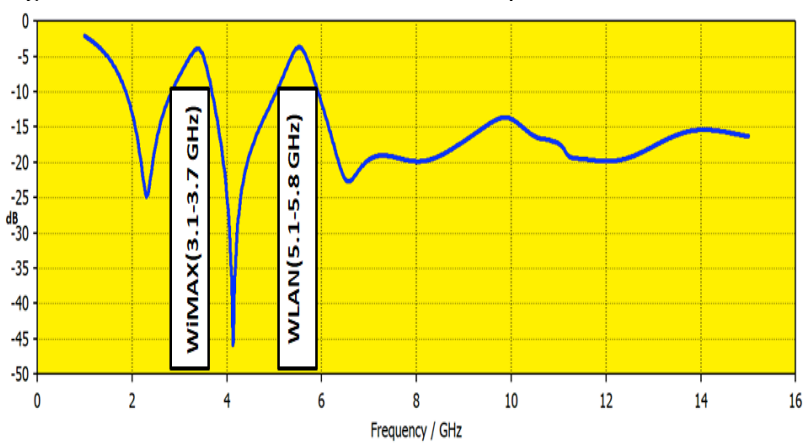

Fig 4. Reflection coefficient of dual notch band monopole antenna with diodes off condition 
The parametric analysis of the circular notch band monopole antenna with respect to length of the ground is performed for optimization and presented in Fig 5. For the length nearer to $19 \mathrm{~mm}$, antenna is showing dual notch band characteristics and for other values the antenna model is showing dual band operation. The circular patch radius also optimized with parametric analysis and presented in Fig 6 . For radius of $10 \mathrm{~mm}$ antenna is showing better reflection coefficient with dual band notching at WiMAX and WLAN bands. Shift in the second notch band can be observed with decrement of radius from 10 to 7 .

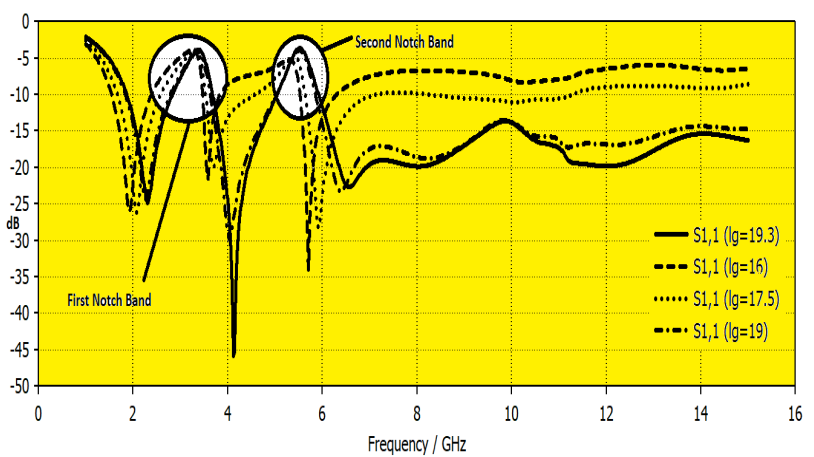

Fig 5. Reflection coefficient with change in ground plane length

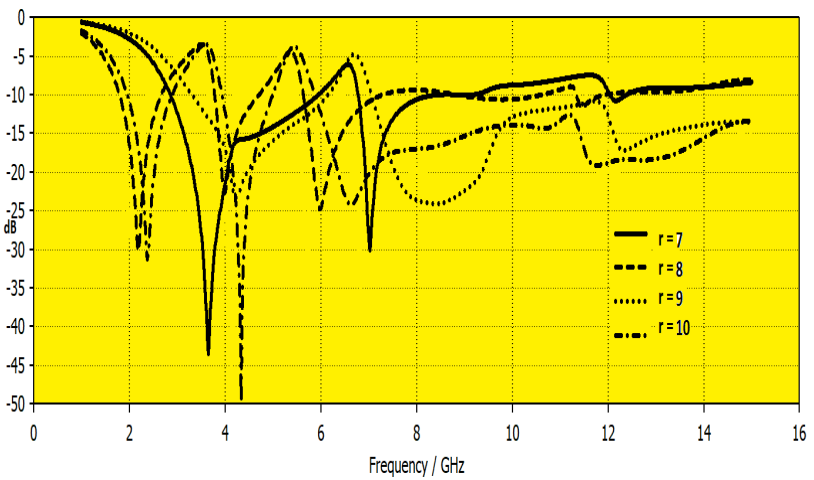

Fig 6. Reflection coefficient with change in radius of the patch
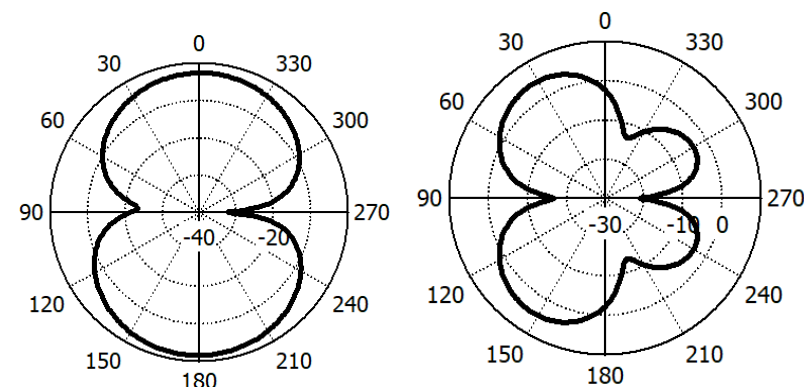

Fig 7. E-Plane and H-Pane radiation patterns of notch band antenna at $2.3 \mathrm{GHz}$

The radiation characteristics of the dual notch band monopole antenna are presented in Fig 7. The modelled antenna is showing monopole like radiation in E-plane and disturbed radiation in H-plane. The cross-polarization level is very low in H-plane. The slots on the radiating element ' $\mathrm{m} 1$ ' and ' $\mathrm{m} 2$ ' are responsible for the notch band characteristics in the antenna. The evidence is in front of us from Fig 8 and 9. The change in ' $\mathrm{m} 1$ ' is providing shift in first notch band towards lower frequency and change in ' $\mathrm{m} 2$ ' also showing the similar kind of shift at second notch.

The proposed reconfigurable antenna with four stubs beside the feed line with combination of diodes interconnection can be observed from Fig 2. The reflection coefficient with change in on and off conditions of the diodes is presented in Fig 10 and 11 for different combinations. When all diodes are in off condition, there is no impact of stubs on the notch and operating bands. For the cases of all diodes in on condition and D1D2 $=$ off, D3D4 $=$ on showing similar kind of results at lower band but small shift in the operating band at higher frequency. When D1D3=off and D2D4=on, the antenna is behaving exactly reverse to dual notch band antenna. The operating bands became notch bands and notch bands became operating bands at lower frequency side. At higher frequency side, antenna showing two more notches at $8 \mathrm{GHz}$ and $12 \mathrm{GHz}$.

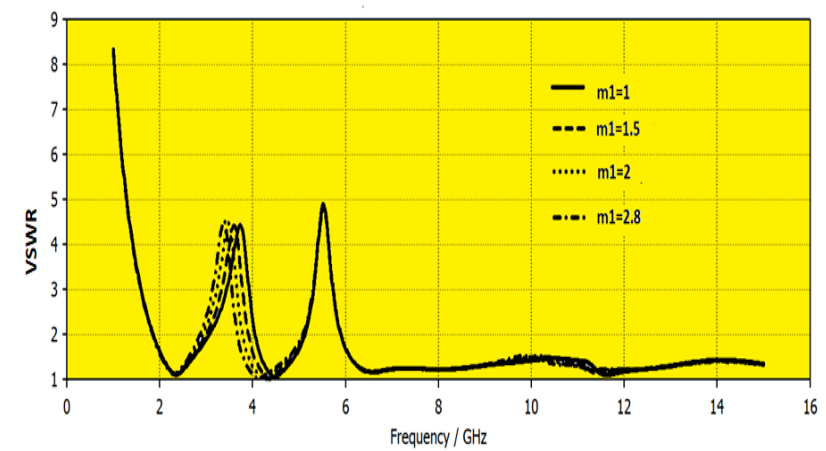

Fig 8. Reflection coefficient with change in slot dimension ' $\mathrm{m}_{1}$ '

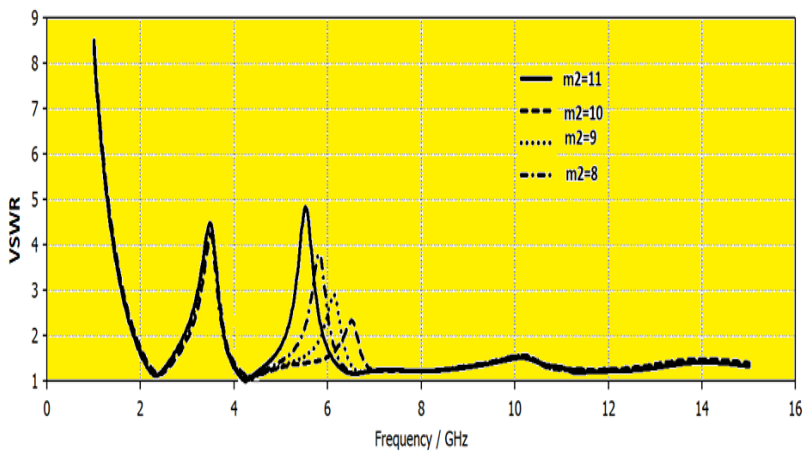

Fig 9. Reflection coefficient with change in slot dimension ' $\mathrm{m}_{2}$ '

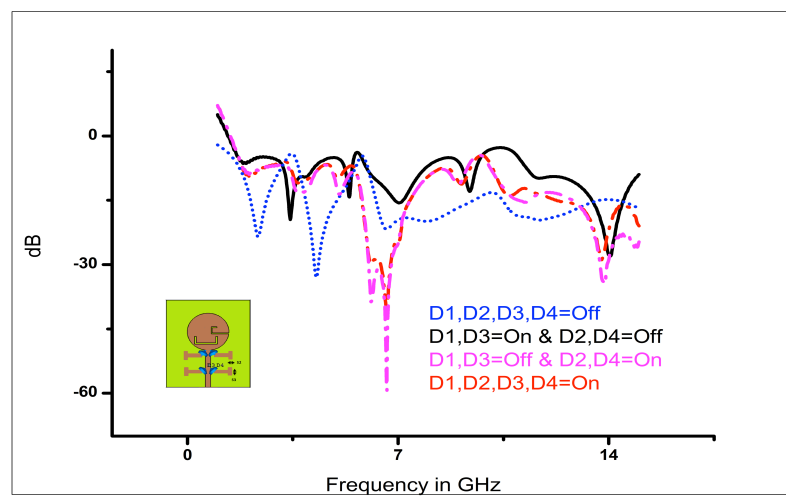

Fig 10. Change in reflection coefficient of proposed model for with diode switching for Case 1

The reflection coefficient with three diodes in on condition and one diode in off condition is presented in Fig 11. Diodes combination of 1 and 2 are providing similar kind of results with dual notching between 3-6 GHz and 8$12 \mathrm{GHz}$. The diodes combination of 3 and 4 are providing almost same results with triple band notching at $4-4.8 \mathrm{GHz}$, 5.2-6 GHz and 10-10.8 GHz respectively. 


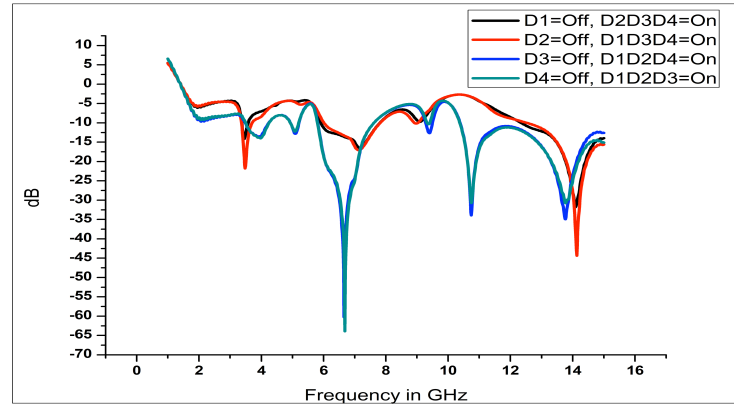

Fig 11. Change in reflection coefficient of proposed model for with diode switching for Case2

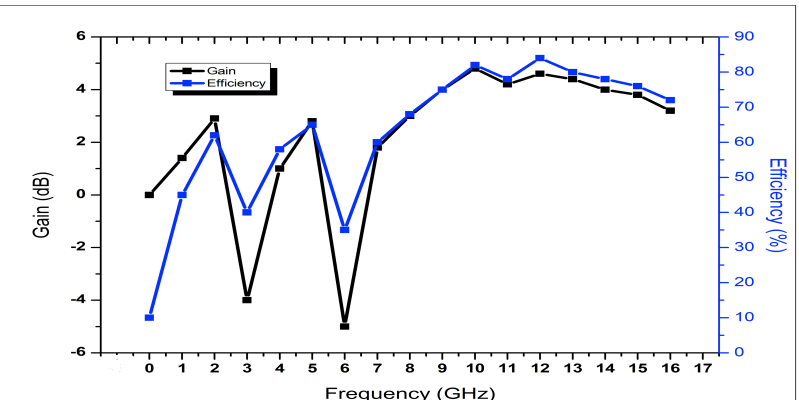

Fig 12. Frequency Vs Gain and Efficiency

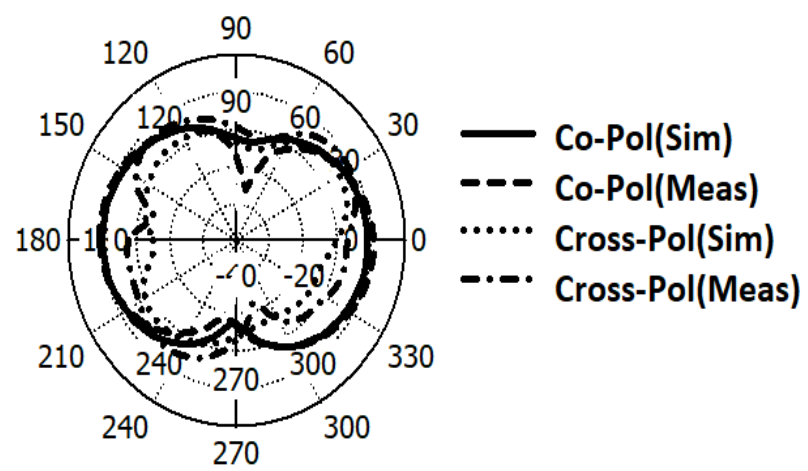

Fig 13. E-Plane Radiation Pattern at $5.6 \mathrm{GHz}$

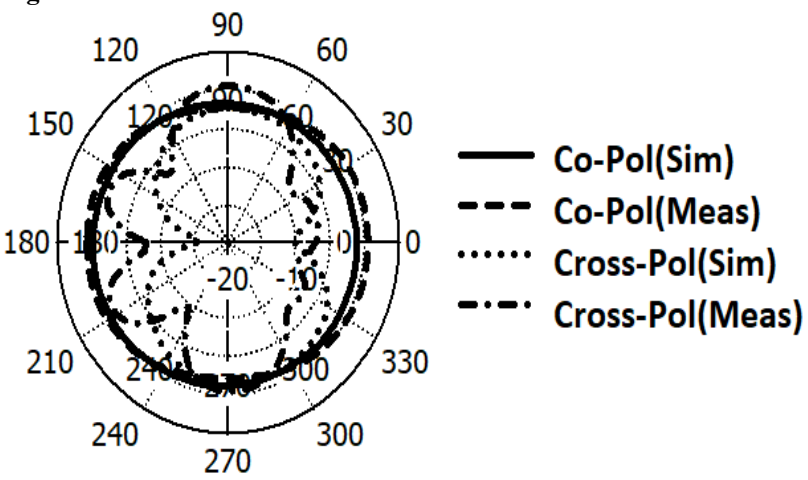

Fig 14. H-Plane Radiation Pattern at $5.6 \mathrm{GHz}$

The gain and the efficiency of the antenna was measured in the wideband and presented in Fig 12. At notch bands the gain is negative and in the operating band we attained a peak realized gain of more than $5 \mathrm{~dB}$. Except at notch bands, the average efficiency of the antenna is around $68 \%$. The simulated and measured radiation pattern of the proposed antenna is presented in Fig 13 for E-plane and in Fig 14 for $\mathrm{H}$-plane. The E-plane pattern is like a monopole pattern and
H-plane pattern is Omni directional pattern with cross polarization less than $-10 \mathrm{~dB}$.
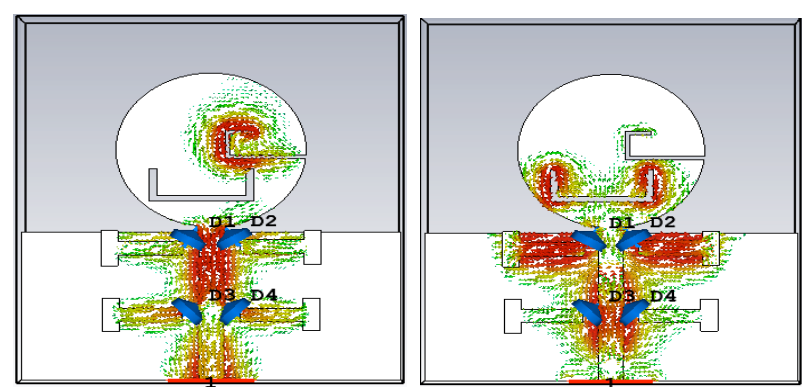

Fig 15. Surface Current distribution, (a) At $3.4 \mathrm{GHz}$, (b) At $5.6 \mathrm{GHz}$

The surface current distribution is providing clear picture regarding the notching characteristics with respect to the slots present on the radiating structure. Fig 15(a) shows the current distribution on the upper slot and the rejection at 3.4 $\mathrm{GHz}$ due to the second slot. Fig 15(b) shows the surface current distribution on the lower slot and the rejection at 5.6 $\mathrm{GHz}$ due to the first slot on the patch structure.

Fig 16 shows the prototyped antenna model before and after connected to biasing wires. The measured reflection coefficient of the proposed antenna model is presented in Fig 17.
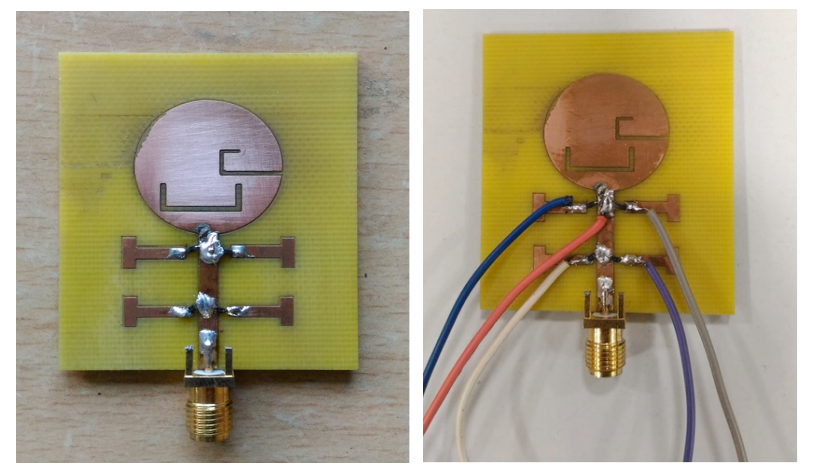

Fig 16. Prototyped Antenna, (a) Before placing Diodes, (b) After placing Diodes

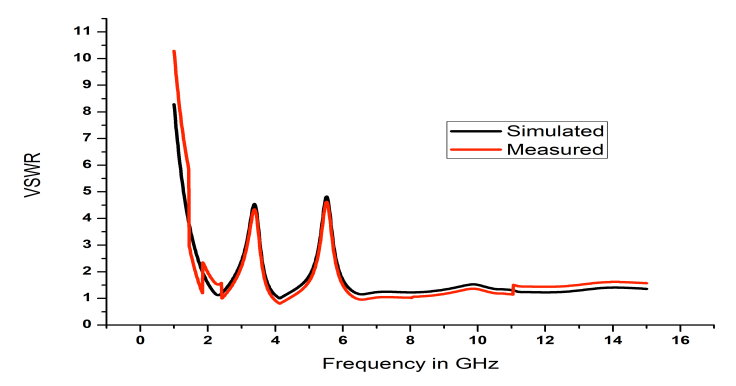

Fig 17. Measured \& Simulated VSWR with diodes off condition

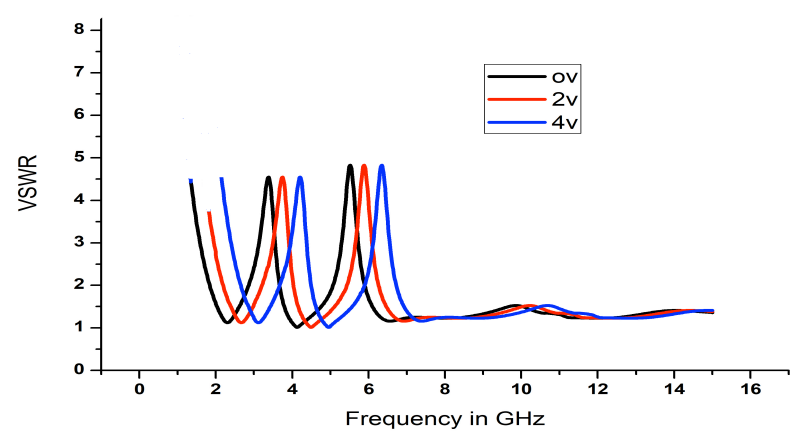

Fig 18. Measured VSWR for DC bias voltage from $\mathrm{V}_{\text {bias }}=0$ to $4 \mathrm{v}$ 
The reflection coefficient measured on Anritsu MS2037C combinational analyzer is matching with simulation results obtained from CST. Connecting wires are attached to a variable power supply and the VSWR is measured for different voltage values. A shift to higher frequency side is observed with increment change in bias voltage and the corresponding frequency reconfigurability can be observed from Fig 18.

\section{Conclusion}

A frequency reconfigurable circular monopole with band notching characteristics are presented in this work. The proposed antenna model is occupying the dimensions of 47X40X1.6 mm on FR4 substrate material. The dual band notch characteristics are obtained at WiMAX (3.1-3.7 GHz) and WLAN (5.1-5.8 GHz) bands. At notch bands the gain is negative and in the operating band, we attained a peak realized gain of more than $5 \mathrm{~dB}$. Except at notch bands, the average efficiency of the antenna is around $68 \%$. Omni directional radiation pattern in H-plane and monopole like radiation in E-plane is obtained from the current model with low cross polarization. The reconfigurable nature of the antenna is observed both in simulation tool and measurement on MS2037C combinational analyser providing satisfactory results with good correlation.

This work can be extended with frequency and polarization reconfigurability, frequency and pattern reconfigurability in the future with experimentation of adding metamaterial structures and electromagnetic band gap loading.

This is an Open Access article distributed under the terms of the Creative Commons Attribution Licence

\section{References}

[1] Schantz, H. G, A brief history of UWB antennas, IEEE A. \& E. Systems Mag, (2004) 23-26.

[2] Chair, R., A. Kishk, and K. F. Lee, Ultrawide-band coplanarwaveguide fed rectangular slot antenna, IEEE Antennas Wireless Propag. Lett, 3(2004) 227-229.

[3] Allam Vamsee Krishna, Planar Switchable Notch Band Antenna with DGS for UWB Applications, Lecture Notes in Electrical Engineering, 434(2017) pp 509-518.

[4] H. Wang and M. Zheng, Triple-band wireless local area network monopole antenna, Microw. Antennas Propag, 2(2008) 367-372.

[5] Ghatak R, Mishra RK, Poddar DR. Perturbed Sierpinski carpet antenna with CPW feed for IEEE $802.11 \mathrm{a} / \mathrm{b}$ WLAN application, IEEE Antennas Wirel Propag Lett, (2008) 742-745.

[6] W.H. Weedon, W.J. Payne, and G.M. Rebeiz, MEMS-switched reconfigurable antennas, Proc. IEEE AP-S Int. Symp. Antennas and Propagation, (2001) 654-657.

[7] S. M. Mahmood and T. A. Denidni, Pattern-reconfigurable antenna using a switchable frequency selective surface with improved bandwidth, IEEE Antennas Wireless Propag. Lett, 15(2016) $1148-1151$.

[8] S.S. Mohan Reddy, P. Mallikarjuna Rao, Design and Analysis of Circular Notch Band DGS Monopole Antenna, Lecture Notes in Electrical Engineering, 434(2017) 409-417.

[9] H. A. Majid, M. K. A. Rahim, M. R. Hamid, and M. F. Ismail, Frequency and pattern reconfigurable slot antenna, IEEE Trans. Antennas Propag, 62(2014) 5339-5343.

[10] S. Nikolaou et al, Pattern and frequency reconfigurable annular slot antenna using PIN diodes, IEEE Trans. Antennas Propag, 54(2006) 439-448.

[11] P. Lakshmikanth, Kh Takeshore, Printed Log Periodic dipole antenna with Notched filter at $2.45 \mathrm{GHz}$ Frequency for wireless communication applications, Journal of Engineering and Applied Sciences, 10(2015) 40-44.

[12] B T P Madhav, VGKM Pisipati1, Liquid Crystal Bow-Tie Microstrip antenna for Wireless Communication Applications, Journal of Engineering Science and Technology, 4(2011) 131134.

[13] B.T.P. Madhav, VGKM Pisipati, Habibulla Khan, P.V. Datta Prasad, Shorting Plate Planar Inverted Folded Antenna on LC Substrate for Bluetooth Application, Journal of Engineering Science and Technology Review, 5(2012) 42-45.

[14] Chien HY, Sim CYD, Lee CH, Dual band meander monopole antenna for WLAN operation in laptop computer, IEEE Antennas Wirel Propag Lett, 12(2013) 694-697.

[15] M. A. Antoniades and G. V. Eleftheriades, A compact multiband monopole antenna with a defected ground plane, IEEE Antennas Wireless Propag. Lett, 7(2008) 652-655.

[16] K. H. Chiang and K. W. Tam, Microstrip monopole antenna with enhanced bandwidth using defected ground structure, IEEE Antennas Wireless Propag. Lett, 7(2008) 532-535.

[17] S.-B. Byun, J.-A. Lee, J.-H. Lim, and T.-Y. Yun, Reconfigurable ground-slotted patch antenna using PIN diode switching, ETRI J, 29(2007) 832-834.

[18] A.C.K. Mak, C.R. Rowell, R.D. Murch, and C.-L. Mak, Reconfigurable multiband antenna designs for wireless communication devices, IEEE Trans. Antennas Propagat, 55(2007) 1919-1928.

[19] B.T.P. Madhav, Harish Kaza, Design and Analysis of Compact Coplanar Wave Guide Fed Asymmetric Monopole Antennas, Research Journal of Applied Sciences, Engineering and Technology 10(2015) 247-252. 